\title{
Journal of Pediatric Neurology \& Medicine
}

\section{The Case of Jean: Releasing the Life Drives Buried in Trauma}

\section{Cristina Lindenmeyer}

Center for Research in Psychoanalysis, Medicine and Society, University of Paris Diderot, France

*Corresponding author: Cristina Lindenmeyer, Associate Professor [Maître de Conférences, HDR] in Clinical Psychopathology and Psychoanalysis, Center for Research in Psychoanalysis, Medicine and Society, University of Paris Diderot, France; E-mail: cristina.lindenmeyer@wanadoo.fr

Received date: April 14, 2017; Accepted date: May 25, 2017; Published date: June 01, 2017

Copyright: $\odot 2017$ Lindenmeyer C. This is an open-access article distributed under the terms of the Creative Commons Attribution License, which permits unrestricted use, distribution, and reproduction in any medium, provided the original author and source are credited.

\begin{abstract}
The following article presents a clinical study of the psychic mechanisms in the case of a six yea old adopted boy. For this child, the loss of his helpful objects (his country, culture and friends) resulted in his psyche being caught up in a melancholic temptation, where the current experience of loss brought to light his previous losses and a fragile narcissism. The case raises clinical and psychopathological questions about the quality of his relationship to the internal object, the nature of his identifications and the formation of his superego, caught up in the melancholic position.
\end{abstract}

\section{Keywords: Cultural change; Loss; Melancholia; Superego}

\section{Introduction}

Moving from one culture to another is not necessarily a trauma in itself. However, it can become one, when the psychic conditions do not allow for the work of libidinal reorganisation that is needed. Certain clinical situations involving children who have undergone such cultural shifts and also were adopted after reaching a certain age show us just how powerful the psychic strategies developed to deal with this trauma can be. Indeed, the changes they face are not insignificant. The child needs to not only libidinally invest his future parents, with all the difficulties this involves [1], but also to leave their country and culture behind, to leave their friends and social group, as well as becoming subject to other regimes and economies of affect [2].

In Freud's second conception of the psychic apparatus, the ego becomes differentiated from the id as a result of the external pressures and requirements it transmits to the centre of the drives, with which it remains in contact via its foundation. Freud argues here that the ego is constituted from the infant's earliest relationships with its first loveobjects. This initial situation, in which the maternal body plays an important role, is constructed against the background of otherness and involves a complex process. The loss of the loved object simultaneously leads to the formation of identifications. These first identifications, which draw on the sexual currents characteristic of the encounter with the object, allow the subject to begin constructing what Freud calls "the psyche". The psychic apparatus thus becomes a space where compromise is possible and where the demands of the drive can be reconciled with the requirements of the outer world.

Following this, a new modification is produced inside the ego. These first identifications, which were related to the infantile narcissism, are further differentiated to form a new agency, which Freud calls the ego ideal or the superego.

The superego is therefore constituted from two elements: on the one hand, "it was the first identification and one which took place while the ego was still feeble", in other words, when, due to his immaturity, the child was still in a dissymmetrical position towards the adult. On the other hand, "it takes the place of the Oedipus complex [3]" and its origins in this complex "bring it into relation with the phylogenetic acquisitions of the id (Ibid)," meaning that there is a transmission of the cultural heritage and the fundamental prohibitions, thus including the individual in a social group. The murder of the father of the horde leaves a trace in each individual; these traces are akin to ancient sediments, which are perpetuated in the continuity of the species [4]. According to Freud, this means that the ego and the superego are constituted not just by the parental authority, but also by the cultural ideals the parents have transmitted.

The functions of the superego, which were introduced by the relationships of love and hate with the first objects, are then established on the intrapsychic level. At first, the child is forced to obey the parents, but once the objects have been introjected in the ego, they acquire a particular place in the superego. The ego is now obliged to obey the superego. The superego commands and criticizes the ego with regards to the demands of the drive, which creates an internal tension between these two agencies. The feeling of guilt is born from this conflict.

Because the superego represents the external world and constitutes "a model which [the ego] can strive to follow [5]", it is easy to understand that a change in the "outside world" in other words, in the symbolic grid created to "read the world" will have direct repercussions on the psyche, with possibly traumatic effects. Based on this, we can ask the following questions: How is the subject going to self-organise psychically to sustain his psychic permanence and, at the same time, invest another culture? What will be the vicissitudes of the drive that result from such cultural crossing? How is the subject going to be able to maintain his own drive dynamics?

In these conditions, can the game of Fort-Da be a model to help us think about crossing boundaries? What often appears in the discourse of patients who have undergone such cultural change is a "time before" and a "time after", expressing two contrary movements of decomposing and recomposing [6].

In Freud's observation of the Fort-Da [7], the traumatic experience of the mother's absence makes the child experience his own sense of permanence, without the mother's containing and reassuring gaze. This experience of the other's presence and absence can become a creative experience if the child is able to count on the identifications formed in 
the encounter with his helpful primary objects. In his essay The Capacity to be Alone, Winnicott reminds us that the infant or small child's capacity to tolerate being alone depends on the ability of the good-enough mother to allow the formation of a reliable internal object. The word "enough" is very important here, because it translates the idea of a mother who can also invest somewhere else and therefore can let the child have an experience of absence that can mobilise his creative capacity. This ability to be alone in the presence of the mother is what creates the child's capacity for play.

However, some children with experiences of loss caused by a change of country seem to perceive this situation as a threat of losing their identifications and seeing their whole symbolic universe collapse. The work of separation puts to test the quality of their narcissistic constructions, i.e., the way in which their object cathexes were introjected. Is this threat a permanent one and does it also put to test their creative capacity, akin to the psychic movement of the Fort-Da game and the capacity to be alone? When there is a feeling that the boundaries of the psychic fabric under construction have been touched, does the subject as a whole pay the price, while letting us believe that a form of existence is possible?

This article presents a clinical study of the psychic mechanisms put in place by a six year old child, following his adoption at the age of four and a move to a new country. For this child, the loss of his helpful objects (his country, culture and friends) became caught up in what I call the "melancholic temptation", where the most recent experience of loss comes to reveal multiple prior losses and a fragile narcissism. This situation raises clinical and psychopathological questions about the quality of the relation to the internal object, the nature of his identifications and the constitution of the child's superego, caught up in the turn towards melancholia.

\section{The melancholic temptation}

In his text Mourning and Melancholia [8], Freud approaches melancholia as one of the psychic solutions a subject can use to deal with the loss of a love-object "or to the loss of some abstraction which has taken the place of one, such as one's country, liberty, an ideal, and so on [9]" simply put, any object in which the subject invests as the guarantor of his feeling of self-permanence. Drawing on Freud's previous argument in On Narcissism: An Introduction [10], this text builds on the earlier theorisation of narcissism and the ego ideal, but adds the description of action of a critical agent present in melancholia. Three elements are put forth as part of the melancholic turn: the loss of an invested object, the ambivalence towards this object and the regression of the libido, which is drawn back to the self.

The question Freud asks is the following: How does the libido, which regresses and turns towards the ego, become lodged in a narcissistic identification? In the melancholic scenario, the subject, instead of withdrawing the libido from the lost object in order to transfer it to a new one, makes a different move. Because the cathected object has disappeared, the libido remains unbound; it withdraws into the ego and is used to establish an identification of the ego with the lost object. This particular use of this type of identification is evidence of a narcissistic fragility, because, in order not to lose the object, the ego instead preserves it inside itself through dissociation. As Freud puts it: "The shadow of the object fell upon the ego [9]".

In taking in the disappointing object, the ego now becomes criticized as if it was indeed this object; it is now itself an object of hate. The self-punishment characteristic of melancholia is in fact addressed to the disappointing and hated object, which is now to be found inside the subject himself. And so, the battle begins, between an ego that has been altered by the introjection, in an effort to preserve the lost object, and the ego-ideal and the cruel agency of the superego, which fiercely attacks this part of the ego. What is very clear in Freud's description is the psychic conflict between the ego and the superego, where the scene of the cruel and deadly punishment remains present. In her comments on this tyrannical force of the melancholic superego, Chabert writes that "the narcissistic power of its links to objects does not always allow for the hate against them to emerge otherwise than through the voice of self-hate [11]."

This is why the quality of the experiences of interiorization of the child's earliest investments and the permanence of his narcissistic foundations are crucial in dealing with situations of loss, as well as in creating new investments. When the child feels unable to capture the gaze of those that have welcomed him into the world, his own capacity to invest becomes compromised.

\section{The constitution of internal objects through identification}

Any situation of loss brings up the need to be able to count on stable objects, which have been introjected in a series of movements of identification.

Freud uses the concept of identification from very early on: initially with regards to the formation of the hysterical symptom [12], but gradually the importance of the notion in psychoanalytic theory increases. In his paper Group Psychology and the Analysis of the Ego [13] and especially three years later in The Ego and the Id, Freud develops the idea that the ego and the superego depend on the child's identifications.

The ego, a "surface entity" [3], is constructed from the traces present in the reminiscences of the infant's early experience with the maternal object and the world around him. The construction of this primary identification, an archaic form of the object relation, begins during the oral stage by investing the object, where it is situated at a stage that is often more of a "merging" than a true binary relationship. In this fantasy of incorporation, the infant lets him be penetrated and preserves the ingested object inside him. This fantasmatic, cannibalistic [4] experience inscribes the sexual pleasure of being penetrated by an object (the breast), the destruction of the incorporated object and the acquisition of its qualities. Identification results from the giving up of the sexual (incestuous) object; the latter is introjected, transforming the ego. A difficulty or impossibility to separate oneself from the object results in melancholia, where the lost object remains forever preserved in the ego via narcissistic identification.

The metaphor of the "dead mother complex" suggested by André Green refers to the encounter with a depressed mother who is physically present, but emotionally absent, which prevents her from being able to invest the child psychically [14]. According to Green [14], if the psyche is placed in such conditions, which it finds unbearable, due to either the object's behaviour or its own aggressive drives, it can construct itself in the mode of negative narcissism.

Initially, the experience of the object's absence allows the child to establish his own psyche. In this situation of absence, the child must rely on the positive traits of the object, which is found-created [15] based on the reality of the experience of encounter, as staged by the game of Fort-Da. However, if these experiences of presence and absence are riddled with problems, the object's absence comes to 
threaten the subject with his own disappearance, forcing him to find a solution in a kind of auto-erotic isolation, a form of narcissism in the negative, as Green puts it. And here we are very far indeed from the Fort-Da.

These psychic constructions are put in place due to the absence of libidinal investment from the object, even though the latter is indeed present. As if the object was psychically registered against the background of a negative presence, leading the child to create a kind of protective doubling around his ego. This psychic construction is organised as a negative identification; the identification with the dead mother will be the child's solution and will determine the future forms of his libidinal investments, both object-related and narcissistic. It is in this sense that Green speaks about a form of destructiveness employed by the psyche as a means of defence. This is indeed a paradox: the psychic apparatus can use destructiveness against destructiveness.

Following upon Green [14], Catherine Chabert's [11] Les voies intérieurs theorizes an intersection between melancholia and masochism. Her argument emphasizes identification as an essential element of one modality of dealing with loss, but she specifically focuses on the crucial role of masochism in certain psychic structures. In other words, she describes the sadomasochist colouring used by certain patients as a form of psychic survival and the central place of hate, which, revived by a new disappointment with the object, is turned against oneself. In this search for pain there is a kind of movement of "melancholic character", without true melancholia necessarily being present. As if suffering was actively sought out to avoid the position of passivity vis-à-vis the disappointment imposed by the other. A lethal battle ensues in the psyche. As Kahn adds, "while the hate of the object is turned into a hate of the self, this process does not result from the drive's reversal properly speaking, but from a regressive solution constituted by the narcissistic destiny of the object relation [16]" This "regressive solution" seems to agree with Klein's argument regarding the much more primitive superego, constituted from the scenarios of primitive sadistic attacks that come into conjunction with the Oedipal conflict [2]. The infant's hate of the object (the breast) when it no longer satisfies his needs transforms it into the "bad breast". This hate is experienced as a fragmentation inside the infant's body. The anxiety and frustration the infant experiences are associated with sadistic fantasies of attacking the breast, devouring it, tearing it apart and destroying it. Then the fear appears of having destroyed the object, which the child continues to love and need. In this atmosphere of the infant's omnipotence, fantasies of reparation are elaborated to "stick the fragments back together". However, they cannot dispel the fear completely. For Klein, unconscious gilt originates from these primitive fantasies of destroying the object.

\section{The case of Jean}

Based on the analytic treatment of Jean, a South-American boy adopted, at the age of four, by European parents, I would like develop a few ideas regarding the negative effects which the child's cultural change and late adoption had on his psyche. For Jean, these changes revealed the constitution of internal objects that did not provide for the psychic work needed to move from one culture to another.

Drawing on the material from this treatment, which lasted six years and was at first conducted twice weekly and later three times weekly, I will present three moments, which will help us understand its trajectory. The first one represents the releasing of the life drives, which had been buried in the traumatic experience; the second the staging and later the elaboration of a tyrannical superego; finally, the third presents the lessening of the superego's attacks against the ego, thanks to the work of transference. The material shows the way in which from an environment that keeps silent about the traumas of Jean's earlier life and the secret melancholia of his adoptive mother emerges subjectivity able to reorganise its object investments, allowing Jean to become aware, with painful intensity, of his unconscious psychic heritage.

As a child, Jean lived until the age of two in a favela. He was abandoned by his biological parents and taken in by a neighbour. $\mathrm{He}$ was later placed in a facility for abandoned children, where he stayed until the age of four, when he was adopted by his parents, a European couple.

According to his adoptive parents, during his first year in France Jean learned French very quickly and stopped speaking his mother tongue completely. Adopting a false self, Jean was thus able to hide, to split off, the violent affects that soon reappeared as a series of symptoms. In the second year, Jean began to behave in ways that his parents found increasingly more difficult to control. They would describe behaviours with a series of repeating characteristics and a predilection for sadomasochistic situations. These would result in endless punishments, as well as moments of violent anger, when Jean's parents had to hold him down on his bed or on the ground, until he was exhausted and calmed down. They were also repeatedly called in by his school teacher, who complained of the boy's "perverse" tendencies: a compulsion to touch other children's genitalia or sniff their underwear. Terribly worried, the parents began to fear that their adoptive son might become a "thug" from the favela and should perhaps be sent back to his home country. With a diagnosis of prepsychosis with perverse traits, he was then referred to me, given my familiarity with his culture of origin.

\section{Releasing the life drives buried in traumatic experience}

I spent considerable time speaking with the parents, trying to find out about the atmosphere in Jean's new family. Then I saw Jean for the first time with his mother. As I usually do, I asked him directly whether he knew why he had come to see me. He answered that he knew it was to "talk about things". I asked his mother to wait in the waiting room. While I was walking her to the door, Jean took his clothes off. Though I was obviously surprised by his behaviour, I decided to say nothing. I received this violent act as a true act, i.e., as giving us access to the psychic material that had emerged under the effect of the intense transferential movements initiated by this first encounter. And yet, I had many questions: What was this gesture trying to stage? Did this situation of meeting a woman (analyst) who is related to his culture of origin make Jean relive the trauma linked to loss and to the encounter with the other, both foreign and familiar? How do we understand this need to enact the unbearable psychic movement, which requires a discharge through bodily movement and getting rid of one's clothes? Were these clothes a representation of his new family and cultural "envelope"? Why did he want to take off everything? I then offered him some toys, crayons and papers. I added that here, he could tell me everything that happens in his mind.

Still standing and milling around the room, Jean looked straight into my eyes and said, with an air of defiance, "It's true that I can do very bad things", repeating a sentence previously uttered by his adoptive mother.

In a clear denial of his immaturity, his posture was that of an adult who provokes terror, whose single movement can destroy all hopes, including his own. A strange adult-like mimic, which expressed the 
dangerous nature of the relationship that might be established with the other. As we know, the identificatory masks used by children conceal their constructions of the self. A construction which in Jean's case I saw as based on his disappointment with the other. Another you cannot rely on, because in any case he is going to let you down, letting go of you as if you were a thing or a piece of rubbish. This was the most disturbing part of his actions: that I would be called to witness this ultimate defeat of oneself that would not be met with any resistance or - worse still - that he took himself for a wicked adult.

\section{I emphasized: "Very bad things".}

He said, as if to convince me: "You know, I can be really bad. Do very bad things." Me: "Perhaps it's your way of saying that you are very unhappy."

After this interpretation, he sat down and began to draw. He drew a large boat and told me: "It's a boat with evil pirates, who are looking for a fight. You are there too."

I asked him to tell me the story of the boat. He said: "It comes from far away, but it remains at sea and attacks the others who try to come close to it."

It was a large boat surrounded by a brilliant sun. The entire page was filled, with no empty space left. The drawing depicted the depressive dimension that followed the manic defences I had seen in the boy's attitude at the beginning of the session. As if this attitude consisted in not feeling anything about all the things he has lost. Listening to him, I imagined that the boat figured his own idea of himself, a child abandoned in the sea [mer] and by the mother [mère]. I noticed that there were two flags in the drawing. He said: "Yes, because they have passed by there, but now they remain at sea. The story's finished." He then grabbed the picture and, rather sadistically, tore it up and threw it in the bin. I took this act as a warning, a kind of condensed scene of a tragic internal drama. In his use of the drawing and its destruction, Jean staged the psychic dynamic fuelled by the hate and the destruction of the object.

I told him: "That's how you feel. Torn up and abandoned, like this piece of paper in the bin." Jean was looking at me attentively. I added another intervention to the interpretation. I picked up the torn pieces and put them in the file I had prepared for him. I told him that in here we stored everything that he produced and that "one day he would be happy to find it again".

Combined with my words, collecting the bits of paper had a containing effect and designated the space of the session as a place that could receive the projections of his inner tyranny.

In leaving his country and culture of origin, Jean experienced a traumatic loss. The current situation of loss came to function as a trigger of all the other instances of abandonment and loss in his history [17]. Caught up in this psychic dynamic of the repetition of loss, his recent experience led to a collapse of his identificatory components, which were needed to resolve his inner conflict. On his arrival France, he spent his first year obeying the harsh demands of the superego, which allowed him to keep up a front and was perhaps necessary for him to invest his "new life" and "new parents". At the same time, all his aggressiveness and sadistic impulses rekindled by the confrontation with loss were repressed. However, this sadistic component was reclaimed by his nascent superego and turned against him. The sadomasochistic dynamic formed between him and his adoptive parents, but also at school, in his constant search for harsh punishments, fuelled his feelings of guilt. This in turn gave rise to murderous and destructive fantasies. He believed that he was a very dangerous person. His bodily enactments and the destruction of the drawing were a condensed representation of this internal drama, in which he was both the victim and the aggressor.

As I have said at the beginning of this discussion, the initial experience of the loss of the object should allow the infant to set up identifications that will form his psyche. However, if this process is impeded, loss is transformed into an experience of disappearance and abandonment. The result will be a narcissistic regression as the destiny of the libidinal investment withdrawn from the disappointing object. Jean was caught up in what I have called a "melancholic temptation" his libido was drawn back into the ego, which then itself became the disappointing and hated object through narcissistic identification. This was the course taken by his drives - masochistically, he submitted himself to the sadistic judgment of his terrifying superego. This masochistic recapture translated into the punishments administered by his parents or the school, where he made himself suffer this kind of self-imposed sadism, while at the same time being able to maintain a relationship with his new environment. In the course of the treatment, this sadomasochistic component began to be transferred - slowly but surely - into the space of the sessions.

In his introductory lecture on Transference, Freud writes: “Thus the transference may be compared to the cambium layer in a tree between the wood and the bark, from which the new formation of tissue and the increase in the girth of the trunk derive" [8]. The metaphor of an intermediary layer, used by Freud to define transference, seems to me an excellent description of the intermediary place in which the space of the session and myself were so quickly "snapped up" by Jean's actions. If the keyword here is "intermediary", this is because the transference retains the power of a movement, one that can reactivate a process previously suspended. Inside/outside, active/passive, presence/absence, love/hate - it is precisely this dual attitude towards the object that transference puts into play. For me, this idea is of primary importance here. It was necessary to let the boy stage the emergence of the ambivalence of his drives.

\section{The tyrannical superego}

The sessions were therefore used to let Jean revive his violent impulses, which were previously the object of his narcissistic identifications. Speaking about child analyses and drive dynamics that are imbricated in the formation of the ego and the superego, still under construction in the child, Kahn writes: "Just like the immutable superego is a superego that attacks in order to punish, the most primitive unconscious is comprised of scenarios in which the primary object is endlessly attacked, regardless of the erogenous zone at play. The analyst is simply the support of the re-actualisation of these repressed scenarios [16]." This idea of providing support to this actualisation is key here.

Starting from my first meeting with Jean, the space of the session functioned as a support to receive his internal scenarios. It was used to make it possible for him to revisit his sadistic violence against both himself and the disappointing object, with which he was narcissistically identified.

Sometimes he would use specific role plays, at other times bodily enactments or terrifying drawings, which were violently destroyed at the end of each session. My role consisted in picking up these torn-up pictures from the bin and putting them into the file. 
While doing so, I always referred to the same rule I had announced at the beginning of the treatment: "I am going to keep everything you do in your file, because one day you will be happy to find it there again." The repeated announcement of the rule guaranteed the protection and permanence of the object, as opposed to letting it disappear.

Jean's games and drawings often featured characters with a strong and cruel super-egoic component. For example, in the games I was sometimes a child who was being mistreated by a tyrannical mother, father or teacher; at other times, he was the mistreated child and I was the villain.

In the course of the sessions, these scenarios repeated without end. Jean's internal battle went on and on, without there ever being a break, a moment of respite. His terrifying characters kept reappearing. Alternatively, the dramatic possibilities provided by the space of the session provoked actions where his body would take over, with a focus on the anal pleasure of expulsion and retention. For example, in the middle of a session, Jean would feel an irrepressible urge to go to the toilet. He could stay there for a very long time and thus envelop me in all his "crap". At other times, the smell of his inner contents would fill the entire consulting room, rendering me passive, subjecting me to what he was subject to. This "crap" was also the visible form of a desire to separate himself from the object, the source of his disappointing, and from his psychic conflict. It was difficult to bear. Sometimes I felt very tired, as if I too had been emptied out at the end of each session.

What seemed important to me during this period of the treatment was not only Jean's sadism, externalised through his violent anility, but also his efforts of testing that these actions will not lead to my destruction. These types of behaviour, which are not unfamiliar to child analysts, can be related to Klein's idea of the analytic situation as a scenario that revives the complex movement of envy and gratitude, of love and hate for the object.

One day, coming back from the toilet, Jean told me: "It's getting better? I was not too long today." This sentence initiated a psychic movement in which the sadistic repetition became addressed to me and thus could allow for a different elaboration. I told him: "Yes, there are many things happening inside you." Hearing this interpretation, he looked at me with apparent relief.

His defences against the terrifying parts of himself gradually became modified and he was becoming able to count on the helpful characters represented on the page. Likewise, in his role plays, the helpful characters were sometimes played by me, sometimes by him. This indicated to me that his internal constraints had changed; the place of the terrifying superego was still present, but he could now count on these helpful objects. These new characters ushered in a superego that was still severe, but now also protective.

However, during this period of the treatment, a question remained unanswered for me, namely the persistence of a scenario, in which Jean was struggling against death. Why could he not make the shifts in identification supported by his new parents? Why would the dynamics of identification that could help him solidify his psychic agencies and deal with his anxiety still not set in?

I had to wait for a long time before Jean could talk to me about his resistance against the new models of identification offered by his adoptive parents. In fact, he would often tell me: "I'm really lucky to have been adopted." Then one day, he said: "My mother told me several times that she had tried to have a child, but it never worked out. So, they decided to adopt a child. That child is me." This sentence brings together several different ideas: a wish for a child condemned to death, the rival brother who triggers murderous wishes and the narcissistic double who becomes the idealised imaginary companion. For Jean, the dead child contaminates the space of identification already undermined by the narcissistic transformations imposed by the loss of his habitual environment. However, the sentence also conceals a melancholic identification with the grieving mother, while simultaneously emphasizing the pathological solution of resisting the identification, even at the cost of sacrificing his psychic life.

Over time, other things shifted as well. Due to the transference we were able to establish and which functioned as a protective shield to contain his primitive anxieties, Jean went through a very long depressive stage, with intense projections of his feelings of abandonment onto the transferential relationship. For example, holidays were always very difficult for him to tolerate and he would regress into a depression.

My absence triggered hate towards the analyst as object, which, once again, became a disappointing object. Jean's psychic solution when faced with this situation was to become immobilised and depressed, his own excitations paralysed. In one session after my return, he told me: "Sometimes I stay in my room and pretend to be playing, but I'm not doing anything. I'm just there, I don't move and I just look at myself in the mirror and I imagine that I am someone else."

Rather than hating me, Jean tried to efface his own drives and even to imagine letting himself die, thus becoming the actor of a murderous despair, which he both suffered from and partook in. The reason was that this hostility was a desire for the other's presence, but also the presence of a desire for death.

\section{The easing of the tyrannical superego}

One day, Jean came to his session looking sad. He sat down and drew a picture for me. He told me that it is a sad boy, who is crying because his cat has died. The cat was lying next to the boy in a pool of blood.

I asked him to tell me the story of the drawing. He said that it was a little boy whose cat had disappeared, and then he added that the cat was dead now, "dead forever." I asked him: "What happened?"

In a tone that numbs all the affect such experience of loss could produce, he said: "The cat disappeared, now it's dead and the boy is sad." Then he added: "But, you know, that's life."

The intensity of the scene invaded the whole room. After a long silence, Jean continued: "Maybe he killed it." He went on: "I'm telling you that it had disappeared. So, the boy was really angry. He killed it. You see, there's blood everywhere." Using a red pencil, Jean added more blood around the dead cat and next to the boy, who in his constructions had now become a raging killer.

Still, this time he did not tear up the drawing, which to me meant that something new was happening in the treatment. Being able to keep the drawing in his file summed up an attempt to elaborate his traumatic experience of loss and hate and thus put in motion a psychic dynamic previously suspended in a single form of repetition.

\section{Conclusion}

On arriving in France, Jean turned his initial attempt at conforming to the loss against him. Subsequently, his symptoms seemed to me 
Citation: Lindenmeyer C (2017) The Case of Jean: Releasing the Life Drives Buried in Trauma. J Pediatr Neurol Med 2: 121. doi: 10.4172/2472-100X.1000121

Page 6 of 6

caught up in a melancholic temptation, as a paradoxical way of tolerating the emergence of his successive experiences of loss.

In the treatment, I was immediately-and, I would say, unwillingly placed in the position of the person who allows this painful experience of the object's presence and absence to emerge [18]. I embodied the object who is welcoming, who receives the subject, but who can also abandon him. Hence, the effect on his ego and the creation of defensive mechanisms that did not manifest only through language, but also through various behaviours and attitudes in the sessions. These were representations of what it was not yet possible to remember; what was transferred was their intensity, using a bodily representation as a cover. As if, instead of remembering the scene of an encounter with a woman-mother-analyst, a scene tainted with disappointment, the memory was enacted; as if Jean's behaviour, instead of freeing him from the charge of affect, was instead trying to preserve even the smallest details of his painful experience of loss, as completely and faithfully as possible [19]. This scene of the disappearance of the loved object and of the psychic violence it produced was reactivated throughout the treatment [1].

The work of transference accompanied Jean on his way towards the kinds of psychic reorganisation that could tackle the traumatic intrusion of his losses. The capacity obtained through analytic work, which was sometimes very difficult and lasted several years, allowed him to perceive the stifling relationships and the deadly climate of his inner world. This progression, in which I was repeatedly forced to see that we were treading on slippery grounds, enabled him to translate the inadmissible pain surrounding his childhood and adoption, to become woefully aware of his own history and to inscribe him again in the cultural world from which he had excluded himself.

\section{References}

1. Roussillon R (2014) Lactualisation de l'archaïque et les conditions de ses après-coups, in Revue Française de Psychanalyse, Lactuel en psychoanalyse, t. LXXVIII,5, pp 1632-1636 Winnicott DW (1954) Two adopted children. The child and the outside world. London: Tavistock: 52-65.
2. Klein K (1932) The psychoanalysis of children. London: Hogarth press. Lévy-Soussan P (2002) Travail de filiation et adoption. R.F.P. 66: 41-69.

3. Freud S (1923) The ego and the Id. Standard edition. London: Hogarth press, pp: 1-66.

4. Freud S (1913) Totem and taboo. Standard edition. London: Hogarth press, p: 162.

5. Freud S (1924) The economic problem of masochism. Standard edition. London: Hogarth press, pp: 155-170.

6. Lévy-Soussan P (2013) Adoption et construction filiative: Réalité, fiction, inconscient, in Ladoption, un roman familiale, Paris Eres: 47-53.

7. Freud S (1920) Beyond the pleasure principle. Standard edition. London: Hogarth press, pp: 1-64.

8. Freud S (1917b) Mourning and melancholia. Standard edition. London: Hogarth press, pp: 237-258.

9. Freud S (1917a) Introductory lectures on psycho-analysis. Standard edition. London: Hogarth press, pp: 430-446.

10. Freud S (1914) On narcissism: An introduction. Standard edition London: Hogarth Press, pp: 67-102.

11. Chabert C (1999) Les voies intérieurs. R.F.P. LXIII: 1445-1488. Chabert C (2011) Le silence de émotions. Paris: Dunod.

12. Freud S (1893) Studies on hysteria. Standard edition. London: Hogarth press, pp: 3-311.

13. Freud S (1921) Group psychology and the analysis of the ego. Standard edition. London: Hogarth press, pp: 65-144.

14. Green A (2001) Life narcissism, death narcissism. Translated by Andrew Weller. London: Free association books.

15. Winnicott DW (1971) Playing and reality. London: Tavistock publications.

16. Kahn L (1987) "Le petit primitif et l'enfant culturel." Cures d'enfance. Paris: Gallimard. Kahn L (1999) Effet ou figure du meurtre? R.F.P. LXIII, pp: 1613-1618.

17. Leys R (2000) Trauma: A geneology. Chicago: University of Chicago Press.

18. Corcos M (2013) Transformer la destructivité dans la cure d'enfants, in La destructivité chez l'enfant, Monographies et Débats de psychanalyse, Paris PUF, pp: 163-177.

19. Fédida P (2007) Humain/déshumain. Pierre fédida, la parole de l’ouvre. Edited by Jacques André. Paris: PUF. 